\title{
A stochastic frontier and corrected Ordinary Least Square models of determining technical efficiency of canal irrigated paddy farms in Tamil Nadu
}

\author{
R.Vasanthi ${ }^{*}$, B.Sivasankari ${ }^{2}$ and J.Gitanjali ${ }^{3}$ \\ ${ }^{1}$ Agricultural College and Research Institute, Killikulam -628252 (Tamil Nadu ), INDIA \\ ${ }^{2}$ Agricultural College and Research Institute, Madurai -625104 (Tamil Nadu ), INDIA \\ ${ }^{3}$ Agricultural Engineering College and Research Institute, Tamil Nadu Agricultural University, \\ Coimbatore-641001 (Tamil Nadu ), INDIA \\ *Corresponding author. E-mail: vasanthi@tnau.ac.in
}

Received: May 31, 2016; Revised received: January 19, 2017; Accepted: April 4, 2017

\begin{abstract}
A comparative study between Stochastic frontier production function and corrected Ordinary Least Square (OLS) were estimated to determine technical efficiency in paddy production. Further, the study has assessed the effect of farm specific socio economic factors affecting the technical efficiency. This study was conducted in Cauvery delta zone of seven taluks about canal irrigation. The number of farmers in canal irrigated region about 109 from seven taluks is considered. The data were obtained from the cost of cultivation scheme of Tamil Nadu centre. The results of Cobb Douglas stochastic production function indicated that fertilizer, seed, pesticide and machine hours significantly influenced yield of paddy. The results also indicated that it will be highly profitable to increase the use of seed, and need to rationalize the labour use and pesticide usage. The effect of qualitative variable namely age and education of the farmer would indicate that the older farmers technical efficiency become less compared to the younger farmer, and also implying that investments on human capital take away their participation from agriculture. As a comparative study in general, COLS produced the lowest mean technical efficiency with 85 percent while the Stochastic frontier analysis produced the highest mean technical efficiency with 90 per cent.
\end{abstract}

Keywords: Canal Irrigation, COLS, Rice, Stochastic Frontier, Technical Efficiency

\section{INTRODUCTION}

Rice is the seed of the grass species Oryza Sativa. Rice is the staple food of over half the world's population. Rice is the main constituent of India's agricultural sector, which occupies 23 percent of the world's rice area and contributes approximately 42 percent of India's food grain production and placed second largest production. As a result of improved technology, the yield of rice has increased from 1.03 t/ha in 1967-68 to 1.75 t/ha in 199 and further increased to 2.17 in 2011-12 (Agricultural Statistics, 2011-2012). The major rice growing States are West Bengal, Uttar Pradesh, Andhra Pradesh, Punjab, Tamil Nadu, Orissa, Bihar \& Chhattisgarh, which together contribute about 72 per cent of the total area and 76 per cent of the total production in our country. In Tamil Nadu, rice is grown over an area of 18 lakh to 20 lakh hectares annually primarily in canal and tank irrigated conditions.

The Economic efficiency is mainly classified into technical efficiency and allocative efficiency (Ogunniyi et al., 2012). Technical efficiency is an indicator of the productivity of the farm and the variation in technical efficiency can reflect the productivity difference across farms. It can be used to increase the productivity, provided the new technologies are used in the field. (Kalirajan et al., 1996). According to Njeru, (2004), the ability of a firm to maximize output given a set resource input is known as technical efficiency while allocative efficiency is the ability of a firm to use inputs optically given their prices and production technology. On the other hand, economic efficiency can be described as capacity of the firm to produce a predetermined quantity of output with minimum cost at a given level of technology. Thus, the growing demand can be met by increasing the technical efficiency.

The present study has assessed the technical efficiency in rice production among canal irrigated farms along with the influence of various socio-economic factors affecting it on the rice farms in Cauvery delta zone of Tamil Nadu state. The main objective of the paper is to compare the technical efficiency between Stochas-tic Frontier Analysis and corrected OLS technique and identify some socio-economic factors which influence its production efficiency.

\section{MATERIALS AND METHODS}

Method of analysis: In the present study, the stochastic frontier production function approach and corrected 
OLS technique were used to measure technical efficiency of rice cultivating farms (Sharma and Dutta, 1997, Sani et al., 2010 and Lawal et al., 2013). In analyzing technical efficiency, it is not the average output, but the maximum possible output obtainable from a given bundle of inputs, is of importance. The frontier production function is defined as the maximum possible output that a farm can produce from a given level of inputs and technology. In stochastic frontier, the disturbance term is decomposed into two components: asymmetric component which captures randomness outside the control of the farmer, such as droughts, floods, etc. and the statistical noise contained in every empirical relationship and the other one-sided component capturing randomness under the control of the farmer (i.e., inefficiency).

Stochastic frontier technique: Stochastic frontier production function was first formulated by Aigner et al. (1977), Meeusen and van den Broek (1977). Assuming that each farm uses $m$ inputs (vector $x$ ) and produces a single output $y$, the production technology of the $\mathrm{i}^{\text {th }}$ farm is specified by the stochastic frontier production function

$$
y_{i}=f\left(x_{i} ; \beta\right) \exp \left(\varepsilon_{i}\right)
$$

Where, $i=1,2, \ldots . n$ refers to farms, $b$ is a vector of parameters and $e_{i}$ is an error term and the function $f(x ; \beta)$

is called the 'deterministic kernel'. The frontier is also called as 'composed error' model because the error term $e_{i}$ is assumed to be the difference of two independent elements,

$e_{i}=v_{i}-u_{i}$

Where, $v_{i}$ is a two sided error term representing statistical noise such as weather, strikes, luck etc which are beyond the control of the farm and $u_{i} \geq 0$ is the difference between maximum possible stochastic output (frontier) $f\left(x_{i} ; \beta\right) \exp \left(v_{i}\right)$ and actual output $y_{i}$. Thus $u_{i}$ represents output oriented technical inefficiency. Thus, the error term $e_{i}$ has an asymmetric distribution. From (1) and (2), the farm-specific outputoriented technical efficiency can be shown as

Table 1. Descriptive Statistics for different variables of 109 farmers.

\begin{tabular}{|c|c|c|c|c|}
\hline Measures & Mean & SD & Minimum & Maximum \\
\hline Yield & 48.6 & 9.8 & 32.1 & 77.3 \\
\hline \multicolumn{5}{|c|}{ Inputs used in rice cultivation in Southern zone } \\
\hline Seed(kg) & 91.4 & 16.6 & 38.5 & 142.9 \\
\hline Fertilizer & 210.1 & 36.1 & 119.4 & 354.5 \\
\hline Pesticide (Rs) & 972.5 & 603.2 & 7.6 & 2625.5 \\
\hline Labour (Hrs) & 573.6 & 431.4 & 255.9 & 4686.9 \\
\hline Machine (Hrs) & 6 & 2.3 & 2.7 & 15 \\
\hline \multicolumn{5}{|c|}{ Socio Economic variables } \\
\hline Age & 58.7 & 12.1 & 21 & 82 \\
\hline Household size & 5.6 & 2.9 & 2 & 13 \\
\hline Area of the farm & 1.48 & 1.47 & 0.1 & 7.14 \\
\hline
\end{tabular}

$$
T E_{i}^{o}=\exp \left(-u_{i}\right)=y_{i} /\left\{f\left(x_{i} ; \beta\right) \exp \left(v_{i}\right)\right\}
$$

Since $u_{i} \geq 0, \quad \mathbf{0} \leq \exp \left(-\boldsymbol{u}_{i}\right) \leq \mathbf{1}$ and hence $\mathrm{O} \leq T E_{i}^{o} \leq 1$. When $u_{i}=0$ the farm's output lies on the frontier and it is $100 \%$ efficient. Thus, the output oriented technical efficiency tells how much maximum output is possible with the existing usage levels of inputs. The 'Cobb-Douglas' function in log form is given by

$$
\ln \left(y_{i}\right)=X_{i} \beta+v_{i}-u_{i}, i=1,2, \ldots n
$$

Where, ${ }^{X_{i}}$ is a vector consisting of the logarithms of $\mathrm{m}$ inputs.

The parameters of the stochastic production frontier and the technical inefficiency effects was estimated simultaneously using the Frontier 4.1 (Coelli, 1996).

Corrected OLS technique: The two OLS (Ordinary Least Square) approaches are Corrected OLS (COLS), developed by Winsten (1957) and Greene (1993) and Modified OLS (MOLS) by Richmond (1974). Both of these methods rely on OLS to estimate the production function parameters, but differ in their treatment of the

OLS residuals ${ }^{\varepsilon_{i}}$. A slightly different approach than OLS involves shifting the line towards the best performing company, which is called Corrected Least Squares methodology (COLS). In a general sense, COLS is merely a shifted average function. Two steps are needed, one to get the expected value of the error term and another to shift or to "center" the equation. The COLS estimator is obtained by turning the least squares estimator into a deterministic frontier model. This is done by shifting the intercept in the OLS estimator upward (for a production frontier) or downward (for a cost frontier) so that all points lie either below or above the estimated function (Maddala, 1999).

The COLS procedure shifts the frontier up by the amount of the largest residual, thus generating a frontier that truly envelops the data. As an example, using our notation, at the first stage a (log-linear) production model such as the following would be estimated by OLS.

$\ln y \mathrm{i}=b_{0}+\mathrm{S} b_{i} \ln x_{i}+e_{i}$

In the second stage the residuals would be utilized to shift the frontier to envelop the data. The maximum residual is denoted as

$\mathrm{e}_{\max }=\max \left(e_{i}\right)$

The COLS intercept would be estimated as,

$b_{C O L S}=b_{0}+\mathrm{e}_{\max }$

This shifts the frontier up so that the observation coinciding with the largest positive residual will be on the frontier, with other observations under the frontier. Efficiency analysis in this approach can be viewed as a relative comparison with the frontier. Frontier observa- 
Table 2. Maximum Likelihood estimates of Cobb Douglas Stochastic frontier function.

\begin{tabular}{lccc}
\hline \multirow{2}{*}{ Variables } & \multicolumn{3}{c}{ Cobb-Douglas } \\
\cline { 2 - 4 } & Coefficient & $\begin{array}{c}\text { Standard } \\
\text { Error }\end{array}$ & $\begin{array}{c}\text { t- } \\
\text { ratio }\end{array}$ \\
\hline Constant & 3.81 & 0.97 & 3.91 \\
ln seed(X1) & $0.26^{* * *}$ & 0.09 & 2.74 \\
ln fer(X2) & 0.02 & 0.11 & 0.15 \\
ln Labr hrs(X3) & $-0.15^{* * *}$ & 0.05 & -3.10 \\
ln machine hrs(X4) & 0.07 & 0.06 & 1.19 \\
ln pest(X5) & $-0.04^{*}$ & 0.02 & -1.78 \\
Const & 0.10 & 0.25 & 0.42 \\
Age & $-0.03^{*}$ & 0.00 & 1.73 \\
Area & 0.00 & 0.01 & 0.33 \\
Edn & $-0.02^{*}$ & 0.02 & -1.86 \\
Household Size & 0.00 & 0.01 & -0.24 \\
S1 & $-0.73^{* * *}$ & 0.14 & -5.30 \\
S2 & $-0.24^{* * *}$ & 0.04 & -5.96 \\
sigma-squared & 0.03 & 0.00 & 7.74 \\
Gamma & 0.87 & 0.04 & 18.8 \\
\hline
\end{tabular}

$*=$ significant at $10 \%$ level, ${ }^{* *}=$ significant at $5 \%$ level, $* * *=$ significant at $1 \%$ level

tion is defined as being fully efficient and other observations receiving efficiency scores relative to the fully efficient observation. Also, another fact is that the COLS frontier does not necessarily bound the data from above as closely as possible (Kumbhaker \& Lovell, 2000) as the corrected frontier is parallel to the OLS frontier by definition.

Data collection and sampling: Paddy is raised in three season's viz., Kar, Samba and Navarai. During the year 2011-12, paddy covered an area of $1.9 \mathrm{mh}$ of which, $1.78 \mathrm{mh}$ ( 93.75 per cent) was irrigated and $0.11 \mathrm{mh}$ (6.25 per cent) was not irrigated. Paddy is grown predominantly in two irrigation regimes namely; canal and tank in Tamil Nadu. As far as paddy is concerned, paddy is hydrophilic crop or water guzzler, i.e., it requires lot of irrigation water. If the water is scarce, it impinges upon the area, production and productivity of rice crop to a great extent. Samba crop accounted for 75.86 per cent of area of $1.9 \mathrm{mh}$ under paddy and 74.95 per cent of total rice production of $7.459 \mathrm{mt}$. Next to Samba, Kar season formed 17.6 per cent of area and 18.56 per cent of total production. Contribution of Navarai crop stood at 6.5 per cent in area coverage and 6.47 per cent in total production of rice. (Season and crop report, 2011-12)

Among the districts in Tamil Nadu, paddy is extensively grown in Tiruvaruar (9.8 per cent), Thanjavur ( 9.5 per cent), Nagapattinam (8.9 per cent), Villupuram and Ramanathapuram ( 6.8 per cent each) districts. The production was found to be higher in Tiruvarur ( 9.8 per cent) followed by Thanjavur (9.5 per cent), and Nagapattinam (8.9 per cent) districts. (Season Crop Report of Tamil Nadu, 2011-12).

The present study undertaken in Cauvery delta zone in the state of Tamil Nadu has estimated the resource use efficiency in rice production under canal irrigated
Table 3. Frequency distribution of Technical efficiency.

\begin{tabular}{lllll}
\hline \multicolumn{2}{l}{ Stochastic Frontier } & & \multicolumn{2}{l}{ Corrected OLS } \\
\hline TE & $\begin{array}{l}\text { No. of } \\
\text { farms }\end{array}$ & Percentage & $\begin{array}{l}\text { No. of } \\
\text { farms }\end{array}$ & Percentage \\
\hline$<70$ & 3 & 2.7523 & 15 & 13.7615 \\
$70-80$ & 11 & 10.0917 & 19 & 17.4312 \\
$80-90$ & 26 & 23.8532 & 20 & 18.3486 \\
$90-100$ & 69 & 63.3028 & 55 & 50.4587 \\
Total & 109 & 100.00 & 109 & 100.00 \\
Mean TE & 0.90 & & 0.85 & \\
\hline
\end{tabular}

farms and has assessed the effect of farm specific socioeconomic factors affecting the technical efficiency. Usually the Stochastic frontier production functions are estimated by using maximum likelihood estimation. But, Corrected OLS method is applied to evaluate the performance efficiency of paddy farms in canal irrigated conditions.

Under the cost of cultivation scheme Stratified random sampling method was adopted. Thanjavur and Thiruvarur districts were selected for canal irrigation under Cauvery delta zone. These districts were selected on the basis of concentration of area under rice cultivation. Data were collected for 2010-11.

In Cauvery delta zone totally seven taluks were selected for the present study about canal irrigation. The 109 farmers in canal irrigated region were selected from seven taluks.

\section{RESULTS AND DISCUSSION}

Empirical model: In the data set, the dependent variable is the yield of rice production measured in quintal per hectare. The inputs considered in the analysis are; (1) Seeds measured in kilograms per hectare, (2) $\mathrm{N}, \mathrm{P}, \mathrm{K}$ fertilizer nutrients drawn from DAP, Urea, Muriate of Potash, 17:17:17 Complex, Ammonium sulphate and Super phosphate measured in kilograms per hectare, (3) Total labour hours comprising of hired (permanent and casual), family and contract labour, measured in working hours, (4) Machine hours (Tractor and power sprayer) measured in hours per hectare, (5) Pesticide expenses measured in rupees per hectare and (6) Trend variable indicating year-1 and year-2.

The explanatory variables also includes the following: (1) Age of the farmer in years, (2) Area in hectares, (3) a dummy variable for marital status of the farmer, (married $=1$, unmarried $=0$ ) (4) Education of the farmer (illiterate (1), upto primary (2), upto secondary (3), upto collegiate (4) and post graduate (5)), (5) Size of the farmer's household (number of family members), (6) dummy variables for seasons 1,2 and 3. The descriptive statistics are presented in Table 1.

The average age of the farmers is found to be 58.7 years indicating that the majority of the people involved in farming activities are in the age group between 50 and 60 years old. The Mean farm size is 1.48 hectares. The average fertilizer rate is $210.14 \mathrm{Kg}$. The 
average rice yield is found to be 48.6 quintal per hectare.

Model results: The estimated parameters of the Cobb Douglas stochastic production frontier are presented in Table 2.

The MLE estimates of Cobb Douglas reported in Table 2 . The coefficients of different input variables revealed that the parameters of seed, labour hours and pesticide cost are significant at $10 \%$ and $1 \%$ level, respectively and hence, playing a major role in influencing rice production. The coefficient for seed happened to be positive and highly significant at one per cent probability level. It indicates that $1 \%$ increase in the usage of seed will increase the output by $0.26 \%$. The coefficient of labour hours was found to be negative and highly significant at one per cent level. This indicated that $1 \%$ increase in the labour hours will decrease the output by $0.15 \%$. The coefficient for pesticide cost was also negative and significant at ten per cent level indicating that $1 \%$ increase in the pesticide usage would also decrease the yield by $0.04 \%$. The coefficient of fertilizer and machine hours were not significant.

It could be observed that MLE for ${ }^{\gamma}$ happened to be 0.87 and highly significant, consistent with the theory that true ${ }^{\gamma}$-value should be greater than zero. The value of $\gamma$-estimate is significantly different from one, indicating that random error is playing significant role to explain the variation in rice production and this is normal especially in case of agriculture where uncertainty is assumed to be a main source of variation. This implies that stochastic frontier model is significantly different from deterministic frontier, which does not include random error. However, it should be noted that 87 per cent variation in output is due to technical inefficiency and 13 per cent is due to stochastic random error.

In order to investigate the determinants of inefficiency, the technical inefficiency model was estimated using Frontier 4.1. The coefficient of education is negative and significant, implying that investments on human capital take away their participation from agriculture.

The coefficient of age happened to be negative and significant, implying that the older the farmer becomes the less his/her technical efficiency in rice production. The coefficients of the seasonal dummies happen to be non-significant and the variable, trend is highly significant.

Technical efficiency: Average estimates of technical efficiency are presented in Table 4 in the form of frequency distribution within a decile range. The estimated mean output oriented technical efficiency is found to be $90 \%$ for 2010-11. Most farms were in the efficiency range of 90-100 per cent followed by $80-90$ per cent. It is also found that there is only 2.7 per cent of farmers were lies in the efficiency range less than 70 per cent in stochastic frontier analysis, but in COLS method 13.76 per cent farmers fall in that efficiency range. Kutaula (1991) used stochastic frontier production function through corrected ordinary least square method for the analysis of resource use efficiency in rice crop grown under land reclamations technology in Haryana. He proved that the sample farmers on an average were successful in achieving 81.79 per cent of technical efficiency. The study by Ayinde et.al., (2009) revealed that the mean technical efficiency at $55 \%, 58$ $\%$ and $57 \%$ for Ofada, Mai-Nasara and NERICA varieties, respectively, implying that the better performance of rice farms in Tamil Nadu.

\section{Conclusion}

From the results of the study it is concluded that seed, labour hours and plant protection chemicals are the inputs that significantly influence the yield, besides the qualitative variable namely age and education. The analysis also indicated the need to increase the usage of seed. The results will also indicate that there is a need to rationalize the use of labour, and pesticide because of their negative influence towards rice production. The coefficient of education is negative and significant, implying that investments on human capital take away their participation from agriculture. The effect of qualitative variable namely age of the farmer which was negative and significant, would indicate that the older farmer's technical efficiency become less compared to the younger farmer. In terms of distribution of technical efficiency among the farmers, the result showed that $69 \%$ of farmers having their technical efficiency above 0.9 . The output oriented mean technical efficiency was found to be $90 \%$ in Stochastic frontier analysis whereas $85 \%$ in COLS method. The general findings from this study indicated that the estimates of technical efficiencies of individual paddy farms, and therefore the mean technical efficiency of the canal irrigated farms, are sensitive to the choice of production frontier estimation method. Of the two models considered for the paddy farm, the statistical deterministic frontier, i.e. COLS produced the lowest mean technical efficiency while the stochastic frontier analysis produces the highest mean technical efficiency in general.

\section{REFERENCES}

Agricultural Statistics (2011-2012). Various issues of Rice Statistical Hand Book; published by Directorate of Economics and Statistics, Government of India

Ogunniyi, L. T, Adepoju, A. A. and Ganiyu, M. O. (2012). A comparative analysis of economic efficiency between traditional and improved rice varieties farmers in oriade local government area of osun state. Trends in Agricultural Economics, 5(3): 70-82

Kalirajan, K. P., Obwona, M. B. and Zhao, S. (1996). A decomposition of total factor productivity growth: The case of Chinese agricultural growth before and after 
reforms. American Journal of Agricultural Economics, 78: $331-338$

Njeru, J. (2004). Factors influencing technical efficiency in wheat production in Kenya. New Research Proposal submitted to African Economic Research Consortium, Nairobi, Kenya

Sharma, V. P. and Datta, K. K. (1997). Technical efficiency in wheat production on reclaimed alkali soils, Productivity. Indian Journal of Agricultural Economics, 38(2): 334

Sani, A, Yakubu, A. A. and Bello, H. M. (2013). ResourceUse efficiency in rice production under small scale irrigation in Bunkure local government area of Kano state. Nigerian Journal of Basic and Applied Science, 18(2): 292-296

Lawal, A. F., Agboluaje, A. A. and Liman, A. (2013). Profitability and productivity of growers of new rice for Africa (NERICA) in the Southern Guinea Savanna of Niger State, Nigeria. PAT; 9 (2): 29-42

Aigner.D .J., Lovell, C. A. K. and Schmidt, P. (1997). Formulation and estimation of stochastic frontier production function models. Journal of Econometrics, 6 (1):21-37

Meeusen, W. and Van J. Broeck. (1977). Efficiency estimation from Cobb-Douglas production with composed error. International Economic Review, 18: 435-444

Coelli, T .J. (1996). Recent development in frontier modeling and efficiency measurement. Australian Journal of Agricultural Economics, 39 (3): 219-245
Winsten, C. B. (1957). Discussion on Mr. Farrell's Paper. Journal of the Royal Statistical Society, Series A (120): $282-284$

Greene, W. H. (1993), The Econometric Approach to Efficiency Analysis, in H. O. Fried, C. A. K. Lovell and S. S. Schmidt (Eds.), The Measurement of Productive Efficiency: Techniques and Applications, London: Oxford Univ. Press, 68-117

Richmond, J. (1974). Estimating the efficiency of production. International Economics Review, 15: 515-521

Maddala, G. S. (1999) Limited Dependent and Qualitative Variables in Econometrics Cambridge University Press, New York

Kumbhaker, S. C. and Lovell, C. A. K. (2000). Stochastic Frontier Analysis. Cambridge University Press, Cambridge.

Kutaula, S. S. (1991). Estimating production technical efficiency for individual farms of paddy and wheat under land reclamation technology. Indian Journal of Agricultural Economics, 48(2): 226-236

Ayinde, O.E., Adewumi, M.O. and Ojehomon, V.E.T. (2009). Determinants of Technical Efficiency and Varietal Gap of Rice Production in Nigeria: A metaFrontier Model Approach. International Association of Agricultural Economics conference, Beijing, China Pp. 16-22 